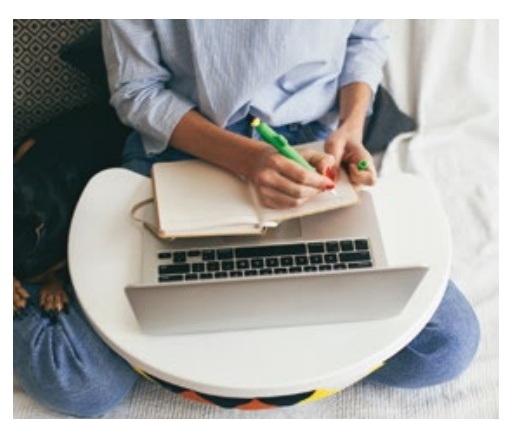

\title{
e-Therapy in primary care mental health
}

\section{Historical perspective}

Australia is a world leader in the development of internet treatment programs for common mental health conditions. In 2007, only a little over $30 \%$ of the one in five Australians with mental health difficulties received any professional help. The internet has come to play an important part in overcoming help-seeking barriers such as stigma, distance, time constraints, treatment availability and cost. ${ }^{1,2}$

In 2001, Christensen and Griffiths, ${ }^{3}$ from the Australian National University, released moodgym - Australia's first online cognitive behavioural therapy (CBT) self-help program. Since then, a range of programs has been developed to address different mental health conditions among specific and general populations.

Despite research evidence to support the efficacy of e-mental health (eMH), ${ }^{4}$ uptake in clinical settings has been slow. In late 2012, the Australian Government funded the e-Mental Health in Practice (eMHPrac) project to provide education to primary care practitioners about the use of online resources for mental health. Table 1 outlines the eMHPrac resources and accredited educational opportunities.

\section{Stepped care and eMH}

The stepped care model of mental healthcare ${ }^{5}$ is based on matching treatment intensity with the severity of patients' mental health problems. Low-intensity interventions can be ideal for patients with mild-to-moderate mental health conditions, and may be more acceptable to patients than referral to a psychologist or pharmacological intervention. Lowintensity interventions are designed to be brief and efficient. General practitioners (GPs) benefit from learning about eMH programs as they are well suited to the large numbers of patients with mild-tomoderate mental health conditions who present to general practice. ${ }^{4}$

\section{Guidelines for use of eMH}

In 2014, The Royal Australian College of General Practitioners (RACGP) released the clinical practice guidelines for eMH. ${ }^{6}$ This consolidated the use of eMH in general practice and outlined ways for GPs to integrate eMH into care. Also in 2014, Australian Family Physician published an article $^{7}$ summarising evidence-based Australian resources. Advances in the $\mathrm{eMH}$ field have led to a wider range of resources and greater sophistication in delivery. Many of these are outlined below.

\section{Online information portals}

The Australian Government's mindhealthconnect website, which previously provided information about online programs and resources, has been relaunched with greater functionality and is now called Head to Health. ${ }^{8}$ This site is designed to help consumers who are concerned about their mental health to complete assessments and receive advice about their mental health needs, including reliable, low-intensity treatment 
Table 1. Educational opportunities and resources for general practitioners in e-mental health

\begin{tabular}{|c|c|c|c|c|}
\hline & Program type & Duration & Accreditation & Delivery \\
\hline eMHPrac webinars & Live interactive webinars & 1 hour each & RACGP and ACRRM & $\begin{array}{l}\text { Online - live or } \\
\text { on demand } \\
\text { www.blackdoginstitute. } \\
\text { org.au/emhprac }\end{array}$ \\
\hline
\end{tabular}

\begin{tabular}{|c|c|c|c|c|}
\hline RACGP webinar & Live webinars & 1 hour & RACGP and ACRRM & $\begin{array}{l}\text { Online on demand } \\
\text { www.racgp.org.au/ } \\
\text { education/courses/ } \\
\text { stepped-care }\end{array}$ \\
\hline Think GP module & $\begin{array}{l}\text { Interactive learning } \\
\text { module }\end{array}$ & 1 hour & RACGP and ACRRM & $\begin{array}{l}\text { Online } \\
\text { www.thinkgp.com.au/ } \\
\text { education/using-e- } \\
\text { mental-health-programs- } \\
\text { your-practice }\end{array}$ \\
\hline Clinical guideline & $\begin{array}{l}\text { Formal guideline from } \\
\text { RACGP and eMHPrac }\end{array}$ & $\mathrm{N} / \mathrm{A}$ & $\mathrm{N} / \mathrm{A}$ & $\begin{array}{l}\text { Online } \\
\text { www.racgp.org.au/your- } \\
\text { practice/guidelines/e- } \\
\text { mental-health }\end{array}$ \\
\hline $\begin{array}{l}\text { eMHPrac resource } \\
\text { guide }\end{array}$ & $\begin{array}{l}\text { Regularly updated list } \\
\text { of Australian evidence- } \\
\text { based online mental } \\
\text { health resources }\end{array}$ & N/A & $\mathrm{N} / \mathrm{A}$ & $\begin{array}{l}\text { Online } \\
\text { www.emhprac.org.au/ } \\
\text { site/assets/files/1120/ } \\
\text { emh_programs_services_ } \\
\text { booklet_updated.pdf }\end{array}$ \\
\hline $\begin{array}{l}\text { Black Dog Institute } \\
\text { eMH and stepped } \\
\text { care workshops }\end{array}$ & $\begin{array}{l}\text { Interactive training } \\
\text { session }\end{array}$ & 2-3 hours & RACGP and ACRRM & $\begin{array}{l}\text { Face-to-face delivery } \\
\text { by Black Dog Institute } \\
\text { GP facilitator by } \\
\text { arrangement with } \\
\text { training organisation }\end{array}$ \\
\hline
\end{tabular}

ACRRM, Australian College of Rural and Remote Medicine; eMHPrac, e-Mental Health in Practice; RACGP, The Royal Australian College of General Practitioners

options. Head to Health does not include evidence ratings for its digital resources. The Beacon website ${ }^{9}$ from the Australian National University provides these, although it is not updated regularly, so newer programs do not appear on the site. GPs can also access information about online resources from the eMHPrac online practitioner resource guide. ${ }^{10}$

\section{Psychoeducation websites}

Many reputable Australian institutions and organisations provide useful mental health information online. Practitioners need to be specific in their website recommendations and familiar with the sites to ensure information is reliable and appropriate. Table 2 provides a list of recommended Australian mental health websites.

\section{Online treatment programs}

In deciding whether to recommend an online treatment program, GPs need to assess whether their patient has the required English language proficiency. In terms of matching programs with symptoms, many online programs are transdiagnostic - that is, designed to target comorbid symptoms of mental illness, including depression, anxiety and stress. myCompass, moodgym, eCouch, and MindSpot are examples of these. Diagnosis-specific programs, such as THIS WAY UP or Mental Health Online, provide specific treatment courses for clinical diagnoses of depression and anxiety.

Consideration of the patient's needs may help decide between programs that are self-help and those that offer guidance. It is also important to consider program costs (a fee applies to THIS WAY UP), whether the program is mobile-enabled, and whether it is necessary to complete the program in a linear fashion or if it can be done in any order. These program details are summarised in Table 3.

Recent developments in eMH treatment programs include the development of new programs and additions to existing programs. 


\section{Table 2. Websites for mental health psychoeducation}

\begin{tabular}{|c|c|c|}
\hline Website name & URL & Audience \\
\hline Head to Health & https://headtohealth.gov.au & General adult \\
\hline beyondblue & www.beyondblue.org.au & General adult \\
\hline Black Dog Institute & www.blackdoginstitute.org.au & General adult \\
\hline $\begin{array}{l}\text { Centre for Clinical } \\
\text { Interventions }\end{array}$ & www.cci.health.wa.gov.au & General adult \\
\hline ReachOut & https://au.reachout.com & Adolescent \\
\hline eheadspace & www.eheadspace.org.au & Adolescent \\
\hline BITE BACK & www.biteback.org.au & Adolescent \\
\hline What Were We Thinking! & www.whatwerewethinking.org.au & Perinatal period \\
\hline $\begin{array}{l}\text { PANDA (Perinatal Anxiety } \\
\text { \& Depression Australia) }\end{array}$ & www.panda.org.au & Perinatal period \\
\hline BeyondNow & $\begin{array}{l}\text { www.beyondblue.org.au/get- } \\
\text { support/beyondnow-suicide- } \\
\text { safety-planning }\end{array}$ & Suicide prevention \\
\hline Operation Life Online & $\begin{array}{l}\text { http://at-ease.dva.gov.au/ } \\
\text { suicideprevention }\end{array}$ & $\begin{array}{l}\text { Suicide prevention in } \\
\text { veterans }\end{array}$ \\
\hline
\end{tabular}

\section{Programs: Self-help category}

Black Dog Institute provides myCompass, ${ }^{11}$ a program comprising modules that can be completed in any order. Users can choose the learning modules that are most appropriate for their needs. myCompass has recently added two new modules: a male-specific module and a module for diabetes-related distress. As with the existing modules, these new modules are divided into three 10-minute sections and take a total of approximately 30 minutes to complete. There are offline exercises between sections.

THIS WAY UP ${ }^{12}$ is a suite of 11 diagnosis-specific treatment programs developed by the Clinical Research Unit for Anxiety and Depression (CRUfAD). The programs have a strong evidence base. ${ }^{12}$ Six of these courses (panic disorder, obsessivecompulsive disorder, depression, social phobia, generalised anxiety disorder and combined depression and anxiety) are now available as apps from the app store. Each program costs $\$ 60$ per enrolment. The cost is designed to be affordable while at the same time improving engagement and adherence. ${ }^{13}$ THIS WAY UP has also added new courses including management of chronic pain, health anxiety, mindfulnessbased therapy, and a teenager-specific course. A sleep management course is also now available free of charge. In addition, a depression program in THIS WAY UP is now available in a Chinese language option.

THIS WAY UP courses require a written prescription from a GP or mental health practitioner. To register as a referring clinician, GPs need to visit the clinician section of the website. Once registered, GPs can refer patients and will receive regular updates on their patient's progress. This process allows GPs to keep track of their patients' use of the program.

Queensland University of Technology has a suite of free online programs called onTrack. ${ }^{14}$ GPs are likely to find the depression and alcohol misuse program especially helpful.

Swinburne University of Technology has a suite of diagnosis-specific programs for depression and specific anxiety disorders called Mental Health Online. ${ }^{15}$

Australian National University provides moodgym and e-couch.${ }^{16}$ Both are linear, transdiagnostic, CBT-based self-help programs designed for youth and adults. moodgym has been used extensively in research and clinical contexts and is available in several languages.

A new suite of programs called My Digital Health has been launched by Federation University. ${ }^{17}$ Currently undergoing formal evaluation, My Digital Health offers wellbeing programs, with a special emphasis on neuroplasticity. The My Digital Health program for anxiety and depression is called LIFE FLeX. There is also Life FLeX for LGBQ people and another for PTSD. Also on the platform is a mindfulness training program, a sleep management program and a program to help reduce benzodiazepine misuse. My Digital Health also offers practitioners the opportunity to build their own digital programs or to modify those already provided.

\section{Programs: Guided self-help category}

THIS WAY UP and Swinburne's Mental Health Online continue to offer optional guidance for users. In the case of THIS WAY UP, a specific request for guidance needs to be made online by the GP, but there is no additional cost for guidance. For Mental Health Online the user can opt to receive guidance, although this costs $\$ 120$.

MindSpot ${ }^{18}$ is delivered by Macquarie University. It provides program-based guidance to every user. Users are contacted by a clinician at enrolment and at completion of each of the lessons. MindSpot now offers several new programs, including a chronic pain management program, a program for teenagers and the Indigenous Wellbeing Program, which is the only online program available specifically for Aboriginal and Torres Strait Islander users. MindSpot is available free of charge to users Australia-wide.

\section{Mobile apps}

The use of mental health apps continues to be a vexed issue, with many mental health apps available but almost all lacking supporting evidence for their use. A recent systematic review revealed that many mental health apps do not have experimental validation..$^{19}$ However, they 


\section{Table 3. Similarities and differences between online treatment programs}

\begin{tabular}{lll}
\hline Cost & Free & Most programs \\
\cline { 2 - 3 } Target group (by diagnosis) & Transdiagnostic & THIS WAY UP \\
\cline { 2 - 3 } & Diagnosis-specific & $\begin{array}{l}\text { moodgym, eCouch, } \\
\text { myCompass, MindSpot }\end{array}$ \\
\hline Program structure & $\begin{array}{l}\text { THIS WAY UP, Mental } \\
\text { Health Online, onTrack }\end{array}$ \\
\hline Self help or guided & Modular & Most programs \\
\cline { 2 - 3 } & Self help & myCompass \\
\cline { 2 - 3 } & Guidance optional & Most programs \\
\cline { 2 - 3 } & & $\begin{array}{l}\text { THIS WAY UP, Mental } \\
\text { Health Online }\end{array}$ \\
& Guided & MindSpot \\
\hline
\end{tabular}

are very convenient and, anecdotally, patients are keen to use them.

One app that GPs may find helpful is beyondblue's BeyondNow Suicide Safety Planning app. ${ }^{20}$ Available free of charge for both iPhone and Android devices, this app allows patients and their practitioners to develop a collaborative safety plan that the patient can have with them at all times on their mobile device. The plan can be modified whenever necessary and can connect the user immediately to crisis services.

A practitioner-facing application of note for those working with Aboriginal and Torres Strait Islander patients is the AIM Hi Stay Strong App for tablets. ${ }^{21}$ This app, developed by the Menzies School of Health Research, allows practitioners to develop a mental health plan with their Aboriginal and Torres Strait Islander patients, providing greater understanding and insight into problems using Indigenousspecific content and images.

Mood tracking is offered by many apps. An example is Mood Prism, ${ }^{22}$ which was developed by Monash University and funded by beyondblue. This app is available in both the Android and iOS (Apple) app stores.

The ReachOut website ${ }^{23}$ provides a database of apps that have been recommended by practitioners; however, as discussed, many of these have not undergone rigorous scientific evaluation. More research is needed in this area.

\section{eMH for special population groups}

GPs may also be aware of other programs developed for special population groups such as children (eg the BRAVE Program for anxious children and adolescents) and parents in the perinatal period, such as the Jean Hailes Foundation's What Were We Thinking! program. More information about these can be found in the eMHPrac resource guide. ${ }^{10}$ Black Dog Institute's eMHPrac webinars also discuss these resources in greater detail (Table 1).

\section{Challenges to using $\mathrm{eMH}$}

Use of eMH may be challenging in patients from non-English-speaking background communities, and in those with poor literacy, low computer competency, limited availability of devices or inadequate internet. Many GPs and their patients, especially those in areas where any kind of psychological care is difficult to access, have used creative solutions to overcome these obstacles. Family, friends and even the practice nurse can demonstrate how to use an online program without interfering with its benefit. Local libraries have computers and internet access, and some GPs have dedicated computers and spaces in their practices for patients to use while completing online programs. Table 4 outlines strategies to improve engagement and adherence with eMH.

\section{Conclusion}

Good quality eMH resources provide GPs with the opportunity to help patients improve their mental health in an efficient and illness-appropriate way, consistent with the principles of the stepped care model of mental healthcare. Many of the available resources are designed to be used as self help, and positive outcomes can be achieved by motivated patients using them in this way. However, GPs who choose to guide patients as they work their way through the programs, seeing them regularly and monitoring their progress, are likely to find patients' engagement with and adherence to the program improves, along with their mental health outcomes. ${ }^{5,13}$ The obstacles to accessing online mental healthcare represent some of the present and future challenges for general practice.

\section{Authors}

Jan Orman MBBS MPsychMed, General Practice Services Consultant, Black Dog Institute, Randwick, NSW. j.orman@blackdog.org.au

Bridianne O'Dea PhD, Research Fellow, Black Dog Institute, Faculty of Medicine, University of New South Wales, Kensington, NSW

Competing interests: Dr O'Dea was an unpaid advisor on the Black Dog Institute eMH Advisory Group from 2015 to 2016.

Provenance and peer review: Commissioned, externally peer reviewed.

\section{References}

1. Australian Institute or Health and Welfare. Mental health services in Australia. Canberra, ACT: AlHW, updated 12 December 2017. Available at https://mhsa.aihw.gov.au/background [Accessed 22 January 2018]

2. Australian Bureau of Statistics. National survey of mental health and wellbeing: Summary of results, 2007. Cat. no. 4326.0. Canberra: ABS, 2008. Available at www.abs.gov.au/ausstats/abs@.nsf/ Latestproducts/4326.0Main\%20Features32007 [Accessed 22 January 2018].

3. ehub Health. moodgym. Sydney: ehubHealth, 2018. Available at www.moodgym.com.au [Accessed 22 January 2018].

4. Andrews G, Cuijpers P, Craske MG, McEvoy P, Titov N. Computer therapy for anxiety and depressive disorders is effective, acceptable and practical health care: A meta-analysis. PLoS One 2010;5(10):e13196. doi: 10.1371/journal. pone.0013196. 


\title{
Table 4. Strategies for improving engagement and adherence in e-mental health
}

\author{
Before you start $\quad$ - Get to know some specific programs \\ - Familiarise yourself with something simple to start with
}

In your practice

- Display material about online treatment options in your waiting room

- Ask your practice nurse to become familiar with the programs you are planning to recommend

In the consultation

- Check your patient's literacy, computer competency and internet/device availability before making a recommendation

- Take patient preferences into consideration

- Present online programs as a credible treatment option

- Show the program to your patient on the computer in your consulting room

- Help (or ask your practice nurse to help) your patient register for the program

- Send an SMS to your patient containing a link to the recommended program

- Warn patients that they may need to provide email addresses and/or telephone numbers

- Reassure them about confidentiality and inform them that they can use an assumed identity if they wish

- Make sure you mention that there will be an assessment tool to complete that measures their progress and allows them to choose another treatment option if the online option is not working or not appropriate

- Discuss with patients the practical aspects of when and where they are going to do the program

- Make a follow-up appointment to see the patient within two weeks to assess progress and encourage adherence

5. Department of Health. The Fifth National Mental Health and Suicide Prevention Plan. Canberra: DoH, updated 17 October 2017. Available at www. health.gov.au/internet/main/publishing.nsf/ content/mental-fifth-national-mental-health-plan [Accessed 22 January 2018].

6. The Royal Australian College of General Practitioners. e-Mental health: A Guide for GPs. East Melbourne, Vic: RACGP, 2015. Available at www.racgp.org.au/your-practice/guidelines/emental-health [Accessed 22 January 2018].

7. Orman J, O'Dea B, Shand F, Berk M, Proudfoot J, Christensen $\mathrm{H}$. e-Mental health for mood and anxiety disorders in general practice. Aust Fam Physician 2014;43(12):832-37.

8. Department of Health. Head to Health. Canberra, ACT: DoH, [date unknown]. Available at https:// headtohealth.gov.au [Accessed 22 January 2018].

9. National Institute for Mental Health Research. Beacon 2.0. Canberra: Australian National University, [date unknown]. Available at https:// beacon.anu.edu.au [Accessed 22 January 2018].

10. E-Mental Health in Practice. eMHPrac e-mental health in practice: A resource guide for practitioners. Brisbane: eMHprac, 2017. Available at www.emhprac.org.au/site/assets/files/1120/ emh_programs_services_booklet_updated.pdf [Accessed 22 January 2018].

11. Black Dog Institute. myCompass. NSW: Black Dog Institute, [date unknown]. Available at www. mycompass.org.au [Accessed 22 January 2018].

12. Clinical Research Unit for Anxiety and Depression, University of New South Wales. THIS WAY UP. Darlinghurst, NSW: St Vincent's Hospital Sydney Ltd, 2018. Available at www.thiswayup.org.au [Accessed 22 January 2018].

13. Hilvert-Bruce Z, Rossouw PJ, Wong N, Sunderland M, Andrews G. Adherence as a determinant of effectiveness of internet cognitive behavioural therapy for anxiety and depressive disorders. Behav Res Ther 2012;50(7-8):463-68. doi: 10.1016/j.brat.2012.04.001.
14. Queensland University of Technology, Queensland Government. OnTrack. Kelvin Grove, Qld: OnTrack, 2010. Available at www.ontrack. org.au/web/ontrack/programs [Accessed 24 January 2018].

15. Swinburne University of Technology. Mental Health Online. Hawthorn, Vic: Swinburne, [date unknown]. Available at www.mentalhealthonline. org.au [Accessed 24 January 2018].

16. e-hub Health. e-couch. Canberra: Australian National University, [date unknown]. Available at https://ecouch.anu.edu.au [Accessed 24 January 2018].

17. Federation University Australia. My Digital Health. Ballarat, Vic: Federation University Australia, 2017 Available at www.mydigitalhealth.org.au [Accessed 25 January 2018].

18. Access Macquarie Virtual Clinic. MindSpot. NSW: Access Macquarie Limited, Macquarie University, [date unknown]. Available at https://mindspot. org.au [Accessed 25 January 2018].

19. Bakker D, Kazantzis N, Rickwood D, Rickard N. Mental health smartphone apps: Review and evidence-based recommendations for future developments. JMIR Mental Health 2016;3(1);e7. doi: 10.2196/mental.4984.

20. beyondblue. BeyondNow - Your suicide safety planning app. Hawthorn, Vic: beyondblue, 2018. Available at www.beyondblue.org.au/get-support/ beyondnow-suicide-safety-planning [Accessed 25 January 2018].

21. Menzies School of Health Research. AIMhi Stay Strong App. Darwin: Menzies School of Health Research, [date unknown]. Available at www. menzies.edu.au/page/Resources/Stay_Strong_ iPad_App [Accessed 25 January 2018].

22. Rickard N, Arjmand H, Bakker D, Seabrook E. Development of a mobile phone app to support self-monitoring of emotional well-being: A mental health digital innovation. JMIR Mental Health 2016;3(4):e49.
23. ReachOut Australia. ReachOut.com: Tools and apps. Pyrmont, NSW: ReachOut Australia, [date unknown]. Available at https://au.reachout.com/ tools-and-apps [Accessed 25 January 2018]. 